\title{
Correlates of compliance with hip-worn accelerometer protocol in adolescents
}

\section{Aderência a protocolo de uso de acelerômetros no quadril em adolescentes}

\section{AUTHOR'S \\ Bruno Gonçalves Galdino da $\operatorname{Costa}^{1}$ (D) Marcus Vinicius Veber Lopes ${ }^{1}$ (D) \\ Luís Eduardo Argenta Malheiros ${ }^{1}$ Jeffer Eidi Sasaki (D) \\ Kelly Samara Silva ${ }^{1}$ iD \\ 1 Universidade Federal de Santa Catarina, Centro de Desportos, Florianópolis, Santa Catarina, Brazil. 2 Universidade Federal do Triângulo Mineiro, Programa de Pós-Graduação em Educação Física, Uberaba, Minas Gerais, Brazil.}

\section{CORRESPONDING}

Bruno Gonçalves Galdino da Costa

bruno.g.costa@posgrad.ufsc.br

Centro de Desportos, Universidade Federal de Santa Catarina, Campus João David Ferreira Lima s/n, Trindade, Florianópolis, Santa Catarina, Brasil.

CEP: 88040-900.

DOI

$10.12820 /$ rbafs. $24 \mathrm{e} 0086$

\section{(c) BY-NC-SA}

This work is licensed under the Creative Commons Attribution-NonCommercial-ShareAlike 4.0 International License.

\begin{abstract}
Accelerometers are widely used to measure physical activity and sedentary behaviour amongst youth, and research participants have to wear the accelerometer for enough time to provide valid estimates of their habitual behaviour. This study aimed to identify correlates of accelerometer wear time in a sample ( $n=142)$ of Brazilian adolescents of the 7 th to the 9 th grade. Students of two middle schools of Florianopolis were invited to participate. The participants answered a questionnaire, wore an accelerometer on the right hip for 10-12 days, and had their height and weight measured. The association of gender, age, socioeconomic position, mother education, conicity index, and self-reported physical activity with accelerometer wear time (minutes), number of days with $\geq 10 \mathrm{~h}$ of valid accelerometer data, and compliance with validation criteria ( $\geq 4$ days with $\geq 10 \mathrm{~h}$ of wear time, including a weekend day) were tested. Accelerometer wear time in minutes was lower in boys than girls (-1014.14, 95\%CI: -1822.91; -205.37). Boys also had less valid days compared to girls (Incidence Risk Ratio = $0.70 ; 95 \% \mathrm{CI}: 0.52 ; 0.94)$ and were less likely to comply with validation criteria (Odds Ratio $=0.29$; $95 \% \mathrm{CI}: 0.12 ; 0.68)$. Higher mother education was associated with increased odds of meeting validation criteria. Factors associated with compliance with accelerometer protocol were sex and mother education. Thus, analyzes should consider the difference in representation of such groups.
\end{abstract}

Keywords: Accelerometry; Motor activity; Cross-sectional study; Adolescents.

RESUMO

Acelerômetros são amplamente utilizados para mensuração da atividade física e comportamento sedentário de jovens, e participantes devem utilizar o acelerômetro por tempo o suficiente para fornecer estimativas de seu comportamento habitual. O presente estudo objetivou identificar correlatos do tempo de uso de acelerômetro em uma amostra $(n=142)$ de adolescentes brasileiros do sétimo ao nono ano. Estudantes de duas escolas de ensino fundamental de Florianópolis foram convidados. Os participantes responderam a um questionário, utilizaram um acelerômetro no quadril direito por 10 a 12 dias e tiveram sua estatura e massa corporal mensuradas. Foram testadas associaçôes de sexo, idade, posição socioeconômica, educação maternal, indice de conicidade e atividade física autorrelatada com tempo de uso do acelerômetro (minutos), número de dias válidos com $\geq 10$ h válidas de dados de acelerômetro e aderência aos critérios de validação dos dados $\geq 4$ dias com $\geq 10 \mathrm{~h}$ de tempo de uso, incluindo um dia de final de semana). O tempo de uso do acelerômetro em minutos foi menor em meninos do que nas meninas (-1014,14; IC95\%: -1822,91; -205,37). Meninos apresentaram menos dias válidos comparadas as meninas (Razão de Risco de Incidência =0,70; IC95\%: 0,52; 0,94) e tiveram uma menor probabilidade de atender aos critérios de validação (Razão de Chance =0.29; IC95\%: 0.12; 0.68). Maior educação materna foi associada com maior chance de atender aos critérios de validação. Fatores associados à aderência ao protocolo de uso dos acelerômetros foram sexo e escolaridade materna. Portanto, análises devem considerar diferenças na representação dentre estes grupos.

Palavras-chave: Acelerometria; Atividade motora; Estudo transversal; Adolescentes.

\section{Introduction}

Accelerometers are widely used in research to measure sedentary behaviour $(\mathrm{SB})$ and physical activity $(\mathrm{PA})$ among adults, elders, and youth ${ }^{1-4}$. Using acceleration has allowed for a more accurate assessment of different $\mathrm{PA}$ and SB characteristics, such as movement intensity, volume and duration, and daily patterns compared to self-reported instruments ${ }^{1}$, which is essential in research with youth, given their limitations in interpreting questions and the memory bias. However, these devices also increase the burden of the research as they have to be worn daily for a week or more, in order to provide a representation of habitual behaviour pattern ${ }^{5}$.

Although the accelerometers can be worn on the wrist or other locations for estimating movement behaviours, most accelerometer processing techniques require data from monitors worn on the hip, close to the centre of mass of the participants ${ }^{5}$, and this practice 
is common in Brazilian studies. The rationale of this protocol is that, in order to move the centre of mass, considerable amounts of energy have to be expended, and this movement is measured by the changes in the acceleration in the vertical axis ${ }^{4}$. The period when the accelerometer is not being worn is considered as non-wear time and is usually identified by algorithms that exclude minutes with consecutive null values of acceleration $^{6}$. To be considered as valid for further analysis, accelerometers have to be worn for 8 to 10 hours daily, depending on the study protocol ${ }^{5}$, and for at least 4 days of the week, usually including 1 or 2 weekend days ${ }^{5,7}$ According to studies, these parameters can vary ${ }^{8}$, which also reflect on the proportion of the sample that provides valid datasets ${ }^{9}$ and their estimates of physical activity and sedentary behaviour ${ }^{10}$.

While some studies show high adherence to accelerometer usage, with $>90 \%$ of children and adolescents providing valid data ${ }^{11,12}$, other studies have shown smaller proportions of adolescents who provided valid datasets ${ }^{12,13}$. When studies have poor compliance with accelerometer usage, this may lead to a subsequent selection bias, which has been cited as a limitation of hip-worn accelerometer protocol ${ }^{8}$. Therefore, some subgroups among adolescents may not be using the accelerometers and could be sub-represented in scientific studies, as highlighted in studies in Scotland ${ }^{14}$, Denmark $^{15}$, and England ${ }^{16}$, where boys and older students were less likely to provide valid accelerometer data. Furthermore, identifying individual characteristics associated with more valid time could be valuable to the development of strategies targeting adolescents who do not provide valid wear time. The aim of the present study was to identify correlates of accelerometer wear time and incompliance with accelerometer validation protocol in a sample of Brazilian adolescents.

\section{Methods}

This cross-sectional study analysed baseline data from the "Movimente" study, a school-based randomised intervention to promote an active lifestyle among adolescents conducted in 2017. Adolescents of the seventh, eighth, and ninth grades from six public schools of Florianópolis, Southern Brazil, participated in the study. The study protocol was approved by the Research Ethics Committee of the Universidade Federal de Santa Catarina (protocol number: 1.259.910), and the project was submitted to the Clinical Trials platform (identifier NCT02944318).
The study protocol was presented and approved by the Education Board of the municipality. The criteria for inclusion of the schools in the study were: i) having the elementary school level grades $(n=27)$; ii) having at least two classes of seventh to ninth grades $(n=21)$; iii) school not going through maintenance $(n=18)$. The 18 schools that met the criteria were invited to participate, and seven principals accepted and signed a written consent form. Additionally, one school was selected for the pilot study, and the remaining six schools were then randomly allocated in the control or intervention groups, paired by size (two average sized schools and one small school in each group). All students of the seventh, eighth, and ninth grades were invited to participate in the study. Students were asked to sign a consent form and provide another consent form signed by their parents or legal guardians. The study protocol included a standardised questionnaire, and adolescents also underwent measurement of height $(\mathrm{cm})$, weight $(\mathrm{kg})$, and waist circumference $(\mathrm{cm})$.

A subsample of two schools was selected to wear accelerometers to measure the habitual levels of PA and sedentary behaviour. Both schools were of small size (six to eight classes) and had similar characteristics. They were chosen due to the limited number of accelerometers required to evaluate all the eligible students from average sized schools. These schools were paired as intervention and control for the "Movimente" project. One school was located in the northern region of the municipality and other in the southern region. ActiGraph accelerometers (models GT3x+ [firmware 3.2.1] and $w G T 3 x+$ [firmware: 1.9.2) were used to measure PA and sedentary behaviour. Trained researchers distributed the accelerometers during class time and oriented the adolescents to wear the accelerometer on the right hip, secured by an elastic band, during their waking hours, except for aquatic activities such as showering, swimming, and surfing. Due to the limited number of devices, participants of the first school wore the accelerometer for 12 days (March $15^{\text {th }}-27^{\text {th }}$ ), and the second school for 10 days (March $31^{\text {st }}-$ April $\left.9^{\text {th }}\right)$. Three messages to stimulate compliance were sent to the participants who accepted being contacted by a messaging application during the data collection phase. Moreover, participants who did not provide valid data were requested to wear the accelerometers for another period of 12 days from the first school (May $4^{\text {th }}-16^{\text {th }}$ ), and 10 days (April $18^{\text {th }}-27^{\text {th }}$ ) from the second school. 
Accelerometer data were collected in $80 \mathrm{~Hz}$ and, subsequently, reintegrated and analysed in activity counts using epochs of $15 \mathrm{~s}$ each. The wear time was determined by excluding periods with 60 consecutive minutes with zero values of movement (which was considered as non-wear time $)^{2}$. A day was considered valid upon presenting at least 600 minutes of wear time. The number of valid weekdays, weekend days, and average valid wear time per day were retrieved for each period during which the participants wore the accelerometer. Habitual PA criteria was defined as providing data for at least three valid weekdays and one valid weekend day. This protocol was in accordance to the instructions for accelerometer use in Brazil ${ }^{17}$.

The information on the gender, age, socioeconomic position, and education of the mother was retrieved using a standardised questionnaire. The gender and age were noted as collected (boys and girls, and age in completed years). For the socioeconomic position variable, a continuous score was calculated using Principal Component Analysis on the number of household items listed by participants (e.g. televisions, washing machines, bathrooms, cars and refrigerators). The household items list was based on the Brazilian Economic Classification Criteria ${ }^{18}$ and the analytical procedures were conducted as recommended. Additionally, the adolescents reported the highest degree their mothers had achieved in the schooling system, and this variable was coded in $\geq 12$ years, $9-11$ years, or $0-8$ years of education accordingly with the degree, for easier comparison with other countries' schooling system. Some students did not know the extent of education their mother had received and were then coded as "Unknown".

Body weight and height were measured once by using, respectively, a calibrated scale to the nearest $0.1 \mathrm{~kg}$ (Welmy 300) and a portable stadiometer calibrated to the nearest $0.1 \mathrm{~cm}$ (Altura Exata brand). Three measures of waist were taken at the narrowest point between the inferior rib by using an inelastic tape measure (Cescorf brand). The first two measures, recorded to the nearest $0.1 \mathrm{~cm}$, were averaged if the discrepancy between them were lower than $1 \%$, otherwise, the median value of the all three measures was recorded. The measures were taken by trained researchers who were calibrated by comparing their measures with an ISAK-Level 1 certificated researcher. All the adolescent's anthropometric measurements were conducted in a private room, using light clothes. The conicity index was calculated and was used as an indicator of body composition ${ }^{19}$.
Self-reported MVPA was measured using an adapted version of the Self-Administered Physical Activity Checklist translated and validated for Brazilian adolescents $^{20}$. Subsequently, the adolescents checked all the physical activities they engage on a typical week out of a list of 22 items, with an option to include non-listed activities. They also provided the frequency (0-7 days/ week) and duration of each session (in min) of each activity. Moderate and vigorous-intensity physical activity (MVPA) was dichotomized in inactive $(0-419$ min of MVPA/week) and active ( $\geq 420 \mathrm{~min}$ of MVPA/ week) according to international guidelines ${ }^{21}$.

The characteristics of the adolescents were described using means and proportions, when appropriate. Generalized linear mixed models were used to test the association of gender, age, socioeconomic position, education of the mother, and conicity index ( $\mathrm{z}$-score) with valid daily wear time (min), valid accelerometer days, and habitual PA criteria compliance provided by each participant (level 1) nested within schools (level 2). The valid wear time variable was $\log$ transformed and a normal distribution family model was generated. Additionally, Poisson and negative binomial regressions were fitted for valid accelerometer days, and as the alpha was observed to be greater than 1, a negative binomial model was chosen. An additional zero-inflated negative binomial model was fitted and compared with the non-zero-inflated model using the Vuong test, which suggested the non-zero-inflated model had a better fit. The coefficients of the negative binomial models were exponentiated to be interpreted as Incidence Risk Ratio (IRR). The associations with habitual PA criteria compliance were tested by fitting a mixed effects binary logistic regression. Consequently, models were checked for collinearity and homoscedasticity, and normality when appropriate. The coefficients of the logistic model were expressed as odds ratio (OR) for easy interpretation.

The initialization, download, processing, and validation of the accelerometer data were conducted on ActiLife, v6.11.8, for Windows. Statistical analyses were attained using $\mathrm{R}$, version 3.5.0 for Windows, with the package lme 4 .

\section{Results}

Figure 1 shows the number of participants of the two schools who received, wore, and provided valid accelerometer data, and were included in the analyses. 


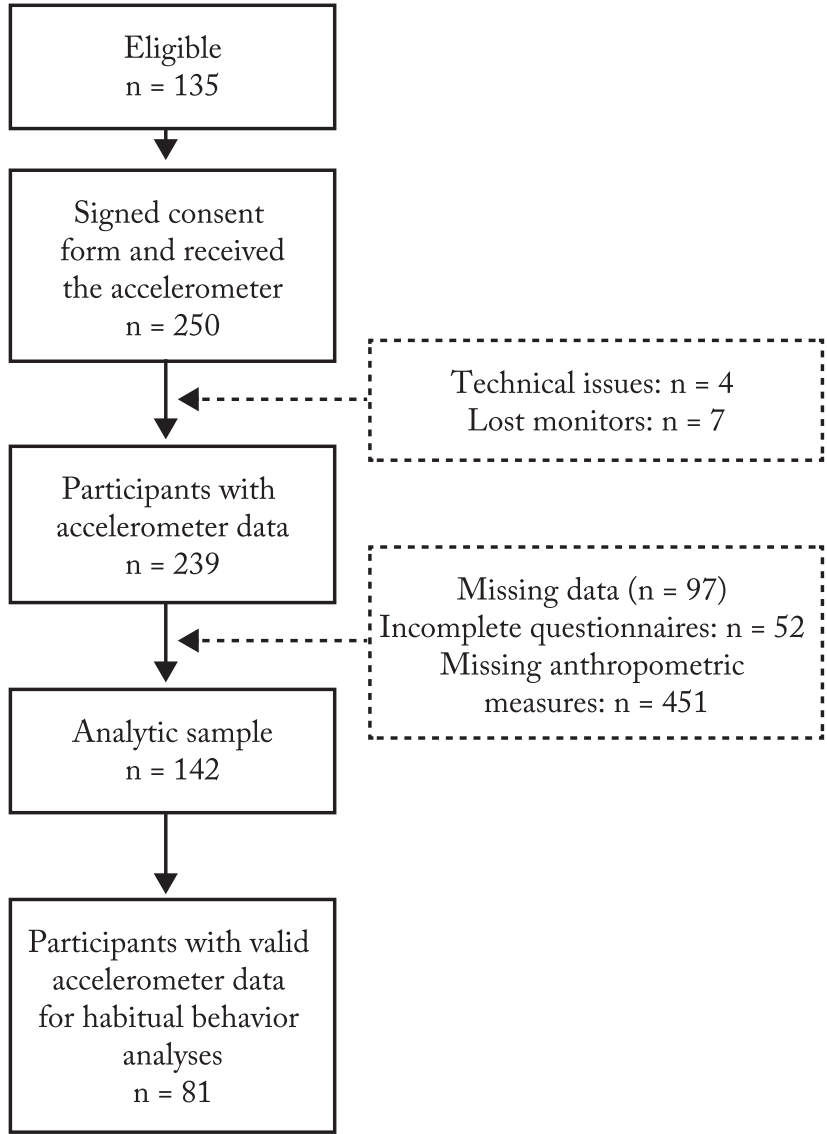

Figure 1 - Flowchart of the participants. Brazil, 2017.

A total of 239 participants wore an accelerometer and provided at least one minute of accelerometer wear time to be included in the analyses. Of the 239 participants with accelerometer data, 208 answered the questionnaire, 195 had their height, weight, and waist circumference measured, and 142 participants provided data in all measurements and were included in the adjusted analyses. Participant characteristics are shown in Table 1.

The distribution of the minutes of valid accelerometer data relative to the number of valid accelerometer days, stratified by those who comply or not with the physical activity guidelines can be observed in Figure 2 .

Results of the adjusted analyses can be observed in Table 2. The mean of accelerometer wear time in minutes was lower in boys than girls $(-1014.14$; 95\%CI: -1822.91; -205.37). The number of valid days and meeting the validation criteria also showed associations for gender, with boys using the accelerometers for fewer days (IRR $=0.70 ; 95 \% \mathrm{CI}: 0.54 ; 0.92)$ and having a lower chance $(\mathrm{OR}=0.29 ; 95 \% \mathrm{CI}$ : $0.12 ; 0.68)$ of meeting the criteria as when compared to girls. The ed-
Table 1 - Participants characteristics. Florianópolis, Brazil. 2017.

\begin{tabular}{|c|c|c|c|}
\hline & $\mathrm{n}$ & $\begin{array}{c}\text { Mean/ } \\
\text { proportion }\end{array}$ & $\begin{array}{l}\text { Standard } \\
\text { deviation }\end{array}$ \\
\hline \multicolumn{4}{|l|}{ Gender } \\
\hline Boys & 63 & 44.37 & \\
\hline Girls & 79 & 55.23 & \\
\hline Age (years) & 142 & 12.94 & 0.87 \\
\hline Socioeconomic score & 142 & 7.00 & 1.31 \\
\hline \multicolumn{4}{|l|}{ Mother education } \\
\hline$\geq 12$ years & 44 & 30.98 & \\
\hline $9-11$ years & 37 & 26.06 & \\
\hline $0-8$ years & 23 & 16.20 & \\
\hline Unknown & 38 & 26.76 & \\
\hline Conicity index* & 142 & 1.08 & 0.06 \\
\hline \multicolumn{4}{|l|}{ MVPA (self-reported) } \\
\hline$\geq 420 \mathrm{~min} /$ week & 49 & 34.51 & \\
\hline$<420 \mathrm{~min} /$ week & 93 & 65.49 & \\
\hline Total accelerometer wear time (minutes) & 142 & 4107.70 & 2290.27 \\
\hline $\begin{array}{l}\text { Number of days with }>10 \mathrm{~h} \text { of } \\
\text { accelerometer data }\end{array}$ & 142 & 3.74 & 2.80 \\
\hline \multicolumn{4}{|l|}{ Valid accelerometer data } \\
\hline Yes & 57 & 40.14 & \\
\hline No & 85 & 59.86 & \\
\hline
\end{tabular}

ucation of the mothers was also associated with meeting inclusion criteria, with those adolescents who did not know the mother's education $(\mathrm{OR}=0.33$; 95\%CI: $0.12 ; 0.93)$ or with mothers whose studied for $9-11$ years $(\mathrm{OR}=0.30 ; 95 \% \mathrm{CI}: 0.11 ; 0.81)$ and $0-8$ years $(\mathrm{OR}=0.20 ; 95 \% \mathrm{CI}: 0.06 ; 0.68)$ presenting lower odds of meeting the criteria compared to the reference group.

\section{Discussion}

The results suggest that a large proportion of adolescents do not provide enough valid data to be included in the habitual PA behaviour analysis. Notably, age, socioeconomic status, conicity index, and self-reported moderate-to-vigorous intensity PA were not associated with the duration of wearing of the accelerometer. Although no difference was observed for these variables when the time was analysed, gender showed significance differences, with boys wearing less than girls. Also, boys had fewer valid days with $10 \mathrm{~h}$ of accelerometer data than girls and were less likely to meet the criteria 
Table 2 - Association between sociodemographic, weight stratus, and MVPA indicators with minutes of valid accelerometer wear time, number of valid days and having valid accelerometer wear data for 4 or more days. Brazil, 2017.

\begin{tabular}{|c|c|c|c|}
\hline & $\begin{array}{l}\text { Minutes of valid accelerometer wear time } \\
\qquad(\mathrm{n}=142)\end{array}$ & $\begin{array}{c}\text { Days with }>10 \mathrm{~h} \text { of valid accelerometer } \\
\text { wear time }(\mathrm{n}=142)\end{array}$ & $\begin{array}{l}\text { Valid accelerometer data } \\
\qquad(\mathrm{n}=142)\end{array}$ \\
\hline & Coefficient $(95 \% \mathrm{CI})$ & $\operatorname{IRR}^{1}(95 \% \mathrm{CI})$ & $\mathrm{OR}^{2}(95 \% \mathrm{CI})$ \\
\hline \multicolumn{4}{|l|}{ Gender } \\
\hline Girls & $\operatorname{Re}^{3}$ & $\operatorname{Ref}^{3}$ & $\operatorname{Ref}^{3}$ \\
\hline Boys & $-1014.14(-1822.91 ;-205.37)^{*}$ & $0.70(0.52 ; 0.94)^{*}$ & $0.29(0.12 ; 0.68)^{*}$ \\
\hline Age (years) & $4.43(-427.92 ; 436.78)$ & $0.97(0.83 ; 1.14)$ & $1.07(0.69 ; 1.64)$ \\
\hline Socioeconomic score & $236.48(-56.35 ; 529.31)$ & $1.07(0.96 ; 1.18)$ & $1.15(0.86 ; 1.55)$ \\
\hline \multicolumn{4}{|l|}{ Mother education } \\
\hline$\geq 12$ years & $\operatorname{Ref}^{3}$ & $\operatorname{Ref}^{3}$ & $\operatorname{Ref}^{3}$ \\
\hline $9-11$ years & $-528.43(-1505.59 ; 448.74)$ & $0.86(0.60 ; 1.22)$ & $0.30(0.11 ; 0.81)^{*}$ \\
\hline $0-8$ years & $-233.8(-1368.47 ; 900.88)$ & $0.83(0.55 ; 1.24)$ & $0.20(0.06 ; 0.68)^{*}$ \\
\hline Unknown & $-1021.99(-2048.81 ; 4.84)$ & $0.73(0.50 ; 1.07)$ & $0.33(0.12 ; 0.93)^{*}$ \\
\hline Conicity index (z score) & $323.69(-73.24 ; 720.61)$ & $1.1(0.96 ; 1.26)$ & $1.41(0.90 ; 2.19)$ \\
\hline \multicolumn{4}{|l|}{ MVPA (self-reported) } \\
\hline$\geq 420 \mathrm{~min} /$ week & $\operatorname{Ref}^{3}$ & $\operatorname{Ref}^{3}$ & $\operatorname{Ref}^{3}$ \\
\hline$<420 \mathrm{~min} /$ week & $-189.95(-977.81 ; 597.92)$ & $0.95(0.71 ; 1.27)$ & $0.64(0.29 ; 1.42)$ \\
\hline
\end{tabular}

*Significant associations at $\mathrm{p}<$ 0.05; 1 = Incidence Risk Ratio; 2 = Odds Ratio; 3 = Reference category.

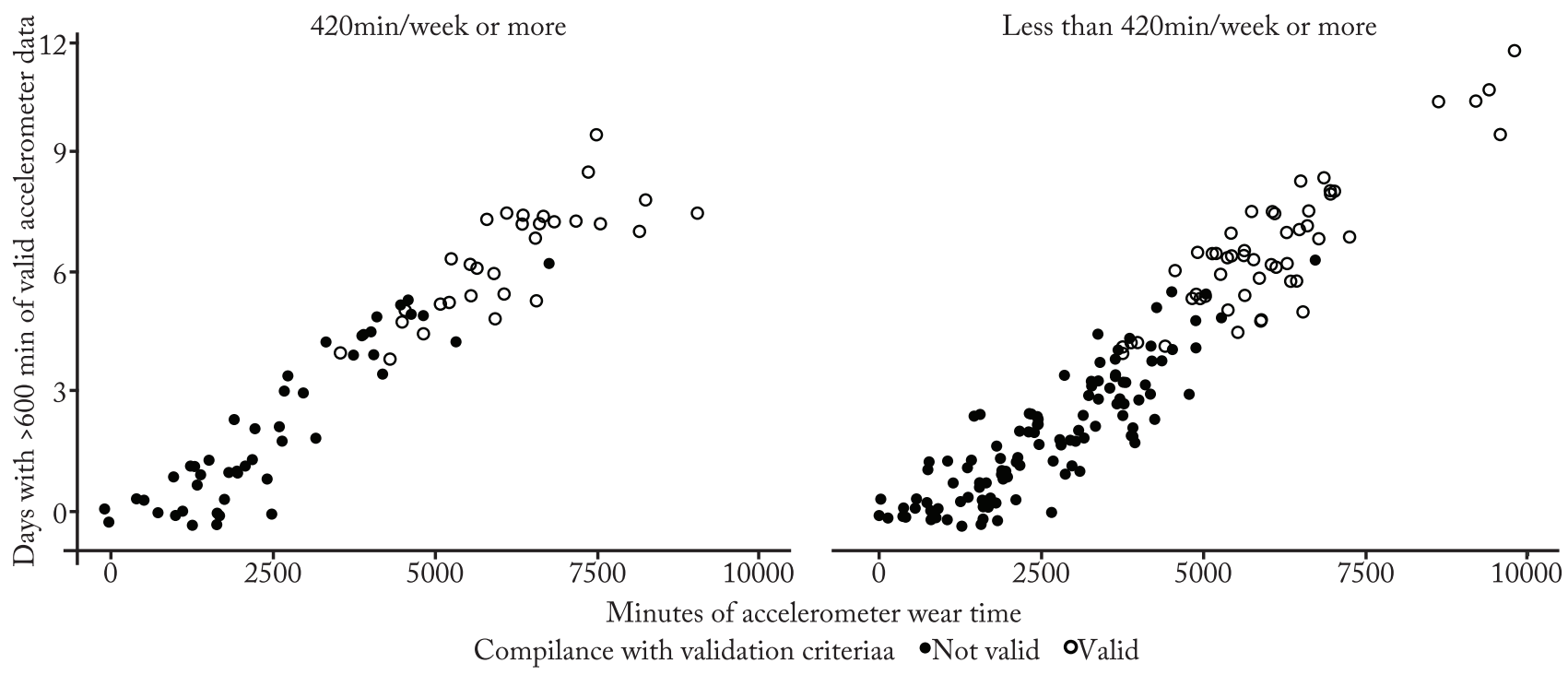

Figure 2 - Time and number of days with $10 \mathrm{~h}$ of accelerometer data of participants who have and have not complied with validation criteria, stratified by those who comply or not the physical activity guidelines. Brazil, 2017.

(10h/day in four days, including one weekend day, after exclusion of periods with $60 \mathrm{~min}$ of consecutive zeros) to be included in the PA analysis. In addition, those with higher maternal education were more likely to meet inclusion criteria and be represented in behaviour analyses. According to the results of the present study, boys and those with high maternal education may be under-represented when analysing accelerometer data using $10 \mathrm{~h} /$ day for 4 days, including one weekend day as criteria for validating accelerometer data, and this may impact estimates, as boys are commonly more ac- tive than girls ${ }^{22}$, and those with higher maternal education are more active than those with less educated mothers ${ }^{22}$. This findings may impact the results from studies where these differences are not checked, and population estimates of physical activity and sedentary behaviour may be lower due to underrepresentation of boys who are more likely to be active ${ }^{22}$.

Notably, information related to the study protocols for accelerometry are often limited ${ }^{3,23}$, and data comparing characteristics of participants with and without valid accelerometer data is scarce. A recent review 
showed that only $33 \%$ of studies reported the number of participants who have not met wear-time criteria, which ranged from 0 to $43 \%$ of the studies' participants $^{12}$. In the present study, we found a very high proportion of adolescents who did not provide valid accelerometer data. Although these differences may often be due to the different protocols adopted for validating accelerometer data ${ }^{5,12,24}$, some studies with similar protocols showed better proportions of valid data ${ }^{11,13,25}$. One example is the International Study of Childhood Obesity Lifestyle and the Environment (ISCOLE), whose methods are described in detail in literature ${ }^{11}$. In the ISCOLE, participants had to wear the accelerometer on the waist for seven consecutive days and provide at least 4 days with 10 or more hours of valid data, a criterion similar to the one used in the present study, with the exception that adolescents were given the accelerometer for 10-12 days in our study. However, in the ISCOLE, only $10 \%$ of the participants did not provide sufficient valid accelerometer data, while this proportion was $76 \%$ in the present study. This remarkable difference does not seem to be explained by gender, age, or any other of the variables analysed, but may be due to the difference in the protocol adopted and the age group. In the present study, adolescents were oriented to remove the accelerometer for sleep and for water-based activities, while in the ISCOLE, participants wore the device at night. This may have prevented the participants from forgetting to wear it when waking up. The age difference may have also played a role ${ }^{26}$, as the participants ( $13 \pm 1$ years) of the present study may have been more resistant to wearing the accelerometer compared to 10-year-old students of the ISCOLE.

While the ISCOLE used a similar protocol, other studies, like the Healthy Lifestyle in Europe by $\mathrm{Nu}-$ trition in Adolescence (HELENA) study used other criteria $^{25}$. Accelerometer data was considered valid on the HELENA after exclusion of 20 min of consecutive zeros, using 8 hours to signify a valid day, and 3 days to analyse habitual behaviour, compared to exclusion of 60 zeros, a 10-hour threshold for a valid day and 4-day for a valid week, including one weekend day in the present study. In the European Youth Heart Study, European (EYHS) 9- to 10-year-olds wore the accelerometer during waking hours for 4 days, 2 weekdays and 2 weekend days, and had to provide 10 valid hours in at least 3 days to be considered valid for analyses, which resulted in $20 \%$ of the sample not reaching these thresholds ${ }^{13}$. Moreover, participants from the HELENA and the EYHS also removed the accelerometer for sleeping, which may have resulted in decreased compliance compared to the participants of the ISCOLE, who also wore it overnight. The age-differences between these studies and the present study may also have played a role in compliance, as studies with younger participants, such as ISCOLE and EYHS may have been less resistant to wearing the accelerometers. It is important to notice that there is no single best recommendation for identifying accelerometer wear time in studies such as ours, and the number of days and hours in a day to validate accelerometer output may vary between social and cultural settings. For example, in Brazil, it is not clear if four days with 10 hours of accelerometer data is enough to estimate the habitual weekly behaviours, and multicentric studies with environmental information are needed to further understand if estimates with such parameters can be generalized.

Comparing the characteristics of participants who provided valid accelerometer data and those who did not is not a common practice but may reveal underlying bias associated with wearing or not wearing the accelerometer and, therefore, under-representing a subgroup in the subsequent analyses. Matthews et al. ${ }^{27}$ compared accelerometer wear time between women and men, and analysed the effects of monitor wear and non-wear time on the relationship with mortality. The authors did not find an association of monitor wear and nonwear time with gender or their outcome. Conversely, studies with Danish ${ }^{15}$, English ${ }^{16}$, and Scottish ${ }^{14}$ adolescents found gender and age differences between those who provided valid accelerometer datasets and those who did not, with boys and older adolescents using the accelerometer for lesser time than their counterparts. Another study revealed that girls reported forgetting to put on the accelerometer, and had to take it off because of diseases or sports competitions for example ${ }^{28}$. In a study with Canadian adolescents aged 10-13 years, participants reported when they took the accelerometers off and their reasons for doing so. The study results indicated that the main reasons for not wearing the accelerometer were forgetting to put it on, and taking it off for engaging in unstructured and structured physical activities ${ }^{29}$. These results suggest that the non-wear time may have an important impact on behaviour estimates and may be related to the reasons why boys and older students wear the accelerometer for lesser time. This subgroup of adolescents is more prone to forget to put the accelerometer on and take it off for activities 
more frequently than their peers. This hypothesis has yet to be tested; however, it may be challenging as it requires that researchers obtain and analyse accelerometer logs from adolescents in large-scale studies. Qualitative studies should be conducted to identify possible barriers perceived by the adolescents that could be changed to improve adherence (e.g. such as appearance of monitors), and improve protocols where the accelerometer is not given without further instructions to the participants. Finally, it is important to consider that protocols where the accelerometers are worn on the wrist and where participants do not remove it for aquatic activities and sleep have shown improved compliance, with large proportions of the studies' samples providing valid data for approximately $24 \mathrm{~h} /$ day $^{12,30}$.

The present study has some limitations, such as the small number of schools included in the analysis and the local characteristics of the sample, which may limit the generalisability of our results. In addition, only small size schools were analysed and the findings should not be extrapolated to the average size schools included in the Movimente study. The small proportion of compliance with the accelerometer protocol is also notable. However, we have used messenger applications and advised teachers to help in encouraging participants to wear the accelerometer. In addition, we have requested those who did not provide valid data for the first time to wear the accelerometer for a second time. The strengths of the present study are the inclusion of a relatively large sample of adolescents who received the accelerometer in a study in a middle-income country, and the use of multilevel regression analyses to account for the variability between schools, which are appropriate for hierarchical data.

A large proportion of adolescents were found to not have provided valid accelerometer data, even when specific strategies were employed to encourage compliance. Additionally, boys were observed to be less likely to provide valid days, to meet inclusion criteria, and the education of the mother was also negatively associated with meeting the inclusion criteria. However, other sociodemographic characteristics as well as weight, status, and self-reported MVPA were not associated with wearing the accelerometer for more or lesser time. Future studies should also describe their protocols in a detailed manner and compare the characteristics of participants who provide valid and non-valid accelerometer data.

\section{Conflict of interest}

The authors declare no conflict of interest.

\section{Funding}

The authors Costa BGG, Lopes MVV, and Malheiros LEA received scholarships from the Coordination for the Improvement of Higher Education Personnel, and the Movimente research project was funded by the National Council for Scientific and Technological Development (CNPq/Edital Universal 14/2014, 446227/2014-5).

\section{Authors' contributions}

Costa BGG, Lopes MVV, and Malheiros LEA participated in the initial concept of the study and data collection. Costa BGG, Lopes MVV, Malheiros LEA, Sasaki JE, and Silva KS participated in the analyzes and interpretation of data, writing, and critical review of the manuscript, with substantial intellectual contributions.

\section{Acknowledgements}

The authors would like to thank: 1) The school community and students that participated in the study for their voluntary contributions; 2) The Board of Education of Florianópolis for the cooperation during the research conduction; 3) The funding agencies: Coordination for the Improvement of Higher Education Personnel and the National Council for Scientific and Technological Development, which provided scholarships for the researchers and the research project Movimente, respectively.

\section{References}

1. Strath SJ, Kaminsky LA, Ainsworth BE, Ekelund U, Freedson PS, Gary RA, et al. Guide to the assessment of physical activity: Clinical and research applications: a scientific statement from the American Heart Association. Circulation. 2013;128(20):2259-79.

2. Troiano RP, Berrigan D, Dodd KW, Mâsse LC, Tilert T, McDowell M. Physical activity in the United States measured by accelerometer. Med Sci Sports Exerc. 2008;40(1):181-88.

3. Ward DS, Evenson KR, Vaughn A, Rodgers AB, Troiano RP. Accelerometer use in physical activity: best practices and research recommendations. Med Sci Sports Exerc. 2005;37(11 Suppl):S582-88.

4. Mathie MJ, Coster ACF, Lovell NH, Celler BG. Accelerometry: providing an integrated, practical method for long-term, ambulatory monitoring of human movement. Physiol Meas. 2004;25(2):R1-20.

5. Cain KL, Sallis JF, Conway TL, Van Dyck D, Calhoon L. Using accelerometers in youth physical activity studies: a review of methods. J Phys Act Health. 2013;10(3):437-50.

6. Choi L, Ward SC, Schnelle JF, Buchowski MS. Assessment of wear/nonwear time classification algorithms for triaxial accelerometer. Med Sci Sports Exerc. 2012;44(10): 2009-16.

7. Migueles JH, Cadenas-Sanchez C, Ekelund U, Delisle Nyström C, Mora-Gonzalez J, Löf M, et al. Accelerometer Data Collection and Processing Criteria to Assess Physical Activity and Other Outcomes: A Systematic Review and 
Practical Considerations. Sports Med. 2017;47(9):1821-45.

8. Troiano RP, McClain JJ, Brychta RJ, Chen KY. Evolution of accelerometer methods for physical activity research. $\mathrm{Br} \mathrm{J}$ Sports Med. 2014;48(13):1019-23.

9. Keadle SK, Shiroma EJ, Freedson PS, Lee I-M. Impact of accelerometer data processing decisions on the sample size, wear time and physical activity level of a large cohort study. BMC Public Health. 2014;14:1210.

10. Banda JA, Haydel KF, Davila T, Desai M, Bryson S, Haskell WL, et al. Effects of Varying Epoch Lengths, Wear Time Algorithms, and Activity Cut-Points on Estimates of Child Sedentary Behavior and Physical Activity from Accelerometer Data. PLoS One. 2016;11(3):e0150534.

11. Tudor-Locke C, Mire EF, Dentro KN, Barreira TV, Schuna JM, Zhao P, et al. A model for presenting accelerometer paradata in large studies: ISCOLE. Int J Behav Nutr Phys Act. 2015;12:52.

12. Montoye AHK, Moore RW, Bowles HR, Korycinski R, Pfeiffer KA. Reporting accelerometer methods in physical activity intervention studies: a systematic review and recommendations for authors. Br J Sports Med. 2018;52(23):1507-16.

13. Ekelund U, Sardinha LB, Anderssen SA, Harro M, Franks PW, Brage S, et al. Associations between objectively assessed physical activity and indicators of body fatness in 9- to 10-y-old European children: a population-based study from 4 distinct regions in Europe (the European Youth Heart Study). Am J Clin Nutr. 2004;80(3):584-90.

14. Buchan DS, McLellan G. Comparing physical activity estimates in children from hip-worn Actigraph GT3X+ accelerometers using raw and counts based processing methods. J Sports Sci. 2019;37(7):779-87.

15. Toftager M, Kristensen PL, Oliver M, Duncan S, Christiansen LB, Boyle E, et al. Accelerometer data reduction in adolescents: effects on sample retention and bias. Int J Behav Nutr Phys Act. 2013;10:140.

16. Mattocks C, Ness A, Leary S, Tilling K, Blair SN, Shield $\mathrm{J}$, et al. Use of accelerometers in a large field-based study of children: protocols, design issues, and effects on precision. J Phys Act Health. 2008;5 Suppl 1:S98-111.

17. Sasaki J, Coutinho A, Santos C, Bertuol C, Minatto G, Berria J, et al. Orientações para utilização de acelerômetros no Brasil. Rev Bras Ati Fis Saúde. 2017;22(2):110-26.

18. Associação Brasileira de Empresas de Pesquisa. Critério de classificação econômica Brasil. ABEP; 2013. [citado em 2019 nov 11]. Disponível em: http://www.abep.org/criterio-brasil.

19. Taylor RW, Jones IE, Williams SM, Goulding A. Evaluation of waist circumference, waist-to-hip ratio, and the conicity index as screening tools for high trunk fat mass, as measured by dual-energy X-ray absorptiometry, in children aged 3-19 y. Am J Clin Nutr. 2000;72(2):490-95.

20. Júnior F, De JC, Lopes A da S, Mota J, Santos MP, Ribeiro JC, et al. Validity and reproducibility of a physical activity questionnaire for adolescents: adapting the Self-
Administered Physical Activity Checklist. Rev Bras Epidemiol. 2012;15(1):198-210.

21. World Health Organization. Global recommendations on physical activity and health. Geneva: WHO; 2010. [citado em 2019 nov 11]. Disponível em: https://apps.who.int/iris/ handle/10665/44399.

22. Bauman AE, Reis RS, SallisJF,WellsJC, Loos RJ,Martin BW. Correlates of physical activity: why are some people physically active and others not? Lancet. 2012;380(9838):258-71.

23. Matthews CE, Hagströmer M, Pober DM, Bowles HR. Best practices for using physical activity monitors in populationbased research. Med Sci Sports Exerc. 2012;44(1 Suppl 1):S68-76.

24. Guinhouya BC, Samouda H, de Beaufort C. Level of physical activity among children and adolescents in Europe: a review of physical activity assessed objectively by accelerometry. Public Health. 2013;127(4):301-11.

25. Ruiz JR, Ortega FB, Martínez-Gómez D, Labayen I, Moreno LA, De Bourdeaudhuij I, et al. Objectively measured physical activity and sedentary time in European adolescents: the HELENA study. Am J Epidemiol. 2011;174(2):173-84.

26. Scott JJ, Rowlands AV, Cliff DP, Morgan PJ, Plotnikoff RC, Lubans DR. Comparability and feasibility of wrist- and hipworn accelerometers in free-living adolescents. J Sci Med Sport. 2017;20(12):1101-06.

27. Matthews CE, Keadle SK, Troiano RP, Kahle L, Koster A, Brychta R, et al. Accelerometer-measured dose-response for physical activity, sedentary time, and mortality in US adults. Am J Clin Nutr. 2016;104(5):1424-32.

28. Catellier DJ, Hannan PJ, Murray DM, Addy CL, Conway TL, Yang $\mathrm{S}$, et al. Imputation of missing data when measuring physical activity by accelerometry. Med Sci Sports Exerc. 2005;37(11 Suppl):S555-62.

29. Borgundvaag E, McIsaac M, Borghese MM, Janssen I. Imputing Accelerometer Nonwear Time When Assessing Moderate to Vigorous Physical Activity in Children. J Phys Act Health. 2017;14(11):852-60.

30. da Silva IC, van Hees VT, Ramires VV, Knuth AG, Bielemann RM, Ekelund U, et al. Physical activity levels in three Brazilian birth cohorts as assessed with raw triaxial wrist accelerometry. Int J Epidemiol. 2014;43(6):1959-68.

Receibed: 04/06/2019 Approved: $26 / 11 / 2019$ 